Passagens. Revista Internacional de História Política e Cultura Jurídica,

Rio de Janeiro: vol. 2 no.5, setembro-dezembro 2010, p. 117 - 139.

\title{
O ESTADO E A MANIPULAČ̃̃ DO MEDO: CRIANCASE MENORES NO CONTEXTO DA POLÍTICA CRIMINAL DA CIDADE DO RIO DE JANEIRO
}

\author{
EL ESTADO Y LA MANIPULACIÓN DEL MIEDO: NIÑOS Y MENORES EN EL \\ CONTEXTO DE LA POLÍTICA CRIMINAL DE LA CIUDAD DE RÍO DE JANEIRO
}

\section{STATE AND THE MANIPULATION OF FEAR. CHILDREN AND MINORS IN THE CONTEXT OF THE CRIMINAL POLICIES OF THE CITY OF RIO DE JANEIRO \\ L'ÉTAT ET LA MANIPULATION DE LA PEUR. ENFANTS ET MINEURS DANS LE CONTEXTE DE LA POLITIQUE CRIMINELLE DE LA VILLE DE RIO DE JANEIRO}

DOI: 10.5533/1984-2503-20102506

Alexandre Miguel França

\section{RESUMO}

Discutindo o medo e a construção de subjetividades oriunda da política criminal e seus efeitos nas crianças de 6 a 10 anos moradoras de uma favela no Rio de Janeiro, o trabalho busca analisar a internalização do controle social, através da percepção feita pelas crianças acerca das operações policiais. Foram realizadas entrevistas e análises de redações e desenhos. As conclusões apontam para o fato de que a política criminal mantém simbolicamente a produção de infâncias desiguais como estratégia de gestão da pobreza, sustentando através das práticas policiais violentas a diferença entre criança e menor, prevista na legislação anterior ao Estatuto da Criança e do Adolescente (ECA). Palavras-chave: medo, controle social, infância.

\section{RESUMEN}

Discutiendo el miedo y la construcción de subjetividades oriunda de la política criminal y sus efectos en niños de 6 a 10 años habitantes de "favelas" en Rio de Janeiro, el trabajo analiza la internalización del control social, a través de la percepción de niños sobre las operaciones policiales. Fueron realizadas entrevistas y análisis de redacciones y dibujos. Las conclusiones apuntam para el hecho de que la política criminal mantiene simbolicamente la producción de infancias desiguales como estrategia de gestión de la pobreza, sustentando a través de prácticas policiales violentas la diferencia entre niño y 
menor, prevista en la legislación anterior al Estatuto de la Infancia y la Adolescencia (ECA).

Palabras-clave: miedo, control social, infancia.

\section{ABSTRACT}

By discussing fear and subjectivity building resulting from the criminal policies and their effects on 6-10 children living in a favela in Rio de Janeiro, this work analyzes the internalization of social control through the way these children perceive police operations. We conducted interviews and writing and drawing analyses. Our conclusions point out that the criminal policies symbolically maintain the production of unequal youths as a strategy to manage poverty, and support, through violent policy practices, the difference between child and minor, established by the legislation enforced before the Estatuto da Criança e do Adolescente (E.C.A. - Child and Adolescent Statute).

Keywords: fear, social control, childhood.

\section{RÉSUMÉ}

En discutant la peur et la construction de subjectivités issues de la politique criminelle et de ses effets chez des enfants de 6 à 10 ans habitant dans une favela de Rio de Janeiro, ce travail analyse l'internalisation du contrôle social au travers de la perception que ces enfants ont des opérations policières. Des entrevues et des analyses de rédactions et de dessins ont été réalisées. Les conclusions indiquent que la politique criminelle maintient symboliquement la production d'enfances inégales comme stratégie de gestion de la pauvreté et soutient, par des pratiques policières violentes, la différence entre enfant et mineur établie dans la législation antérieure à l'Estatuto da Criança e do Adolescente (E.C.A. - Statut de l'Enfant et de l'Adolescent).

Mots-clefs : peu, contrôle social, enfance.

\section{Introdução}

Nem todas as crianças vingam, bateu-lhe o coração.

Como introdução ao presente trabalho, que discute alguns dos principais aspectos de pesquisa realizada em dissertação de mestrado recentemente defendida ${ }^{1}$, nada melhor do que recorrer a Machado de Assis, autor que, de certa forma, possibilitou a

\footnotetext{
${ }^{1}$ França, Alexandre Miguel (2009). A política criminal e a construção de infâncias desiguais: o caso dos meninos impossíveis de Pasárgada, defendida no âmbito do Programa de Pós-Graduação em Sociologia e Direito - PPGSD/UFF, sob orientação da professora Dra. Vera Malaguti Batista, com apoio da Capes.
} 
verdadeira compreensão do presente tema de estudo e que conseguiu, talvez em uma única frase como a da epígrafe, resumir muito do que se pretende trabal har aqui. Trata-se da frase final do conto "Pai contra mãe", escrito em 1906.

No referido conto, o autor narra a história de Cândido Neves, que em razão da pobreza e da dificuldade em trabalhar passou a exercer o ofício de pegar escravos fugidos. Casado com Clara, costureira, e morando também com a tia da moça, o personagem e sua família vivem um grande drama que acompanha o nascimento de seu primeiro filho. Prestes a chegar ao mundo o menino, o pai começa a enfrentar dificuldades em seu ofício devido à grande concorrência e os lucros começam a escassear. Despejados pelo dono da casa dois dias antes do nascimento da criança, em razão das dívidas, ganha força por parte da tia da moça, Mônica, a idéia na qual já vinha insistindo: entregar a criança na "Roda dos Enjeitados". Entretanto, numa última esperança, Cândido revira os antigos anúncios de jornal que davam conta de escravos fugidos e da recompensa quando um the chama atenção pelo valor: era o anúncio da escrava Arminda, no rastro da qual já havia corrido sem sucesso.

Sem conseguir, no entanto, encontrá-la, numa noite decide o personagem entregar seu filho. Quando ia a passos lentos para a Roda, Cândido avista a "mulata fujona", deixa seu filho em uma farmácia e corre à sua cata. É o fim do seu desespero, mas não do sofrimento. Grávida, Arminda suplica pela sua soltura, uma vez que seria certamente açoitada pelo seu senhor, o que seria terrível em seu estado. Jogando a culpa na mulata, pela "irresponsabilidade" de fazer filhos e depois fugir, Cândido sequer pensa em desistir e arrasta a fujona até a casa do senhor. Lá chegando, após o pagamento dos cem mil réis de gratificação a Cândido, cansada pela luta e numa mistura do que Machado de Assis define como medo e dor, a escrava, no chão, aborta a criança. Com a recompensa, voltam pra casa Cândido e seu filho. A criança filha da escrava morre antes mesmo do nascimento e dá continuidade a vida em família de Cândido Neves, que termina a história com a certeza da frase da epígrafe.

Apesar da clareza com a qual Machado de Assis nos mostra a violência nas relações sociais do Brasil escravocrata, é importante pensar quais as possíveis permanências históricas ${ }^{2}$ destas violências no campo social hoje e, neste sentido, problematizar a última frase do conto e reescrevê-la agora, com uma interrogação no

\footnotetext{
${ }^{2}$ Neder, Gizlene (2005). Discurso Jurídico e Ordem Burguesa no Brasil, Porto Alegre: Sérgio Fabris Editor.
} 
final. Neste sentido, entendemos como fundamental indagar se existiriam hoje algumas "crianças" que não podem "vingar".

\section{Política criminal na cidade do Rio de Janeiro}

No momento em que prestamos mais atenção a algumas frases ditas pelas autoridades da segurança do Estado, podemos observar indícios bem claros sobre a forma como a política criminal vem sendo conduzida na cidade do Rio de Janeiro ${ }^{3}$. É possível observar nas falas como a ideia de degenerescência de Benedict Morel ${ }^{4}$ ainda tem forte presença no imaginário, sempre associada com a ideia da existência de áreas perigosas que são foco endêmico de criminalidade e sujeira ${ }^{5}$. Além disso, é possível perceber também a demonização, o estigma e a associação do crime com a barbárie, que historicamente justificam diversos tipos de violência contra as camadas populares da cidade. ${ }^{6}$

A associação destes discursos com os resultados práticos da política adotada nos revela que não vivem apenas de discurso as autoridades do Estado, mas estão realizando na prática aquilo que prometem ou pregam. Os números de "autos de resistência", quando a técnica policial afirma que ocorre morte por resistência do opositor, que dão conta de 1.260 mortes em 2007 e 1.066 mortes até novembro de 2008 ${ }^{7}$, podem comprovar, na prática, o que prega o discurso: a truculência e a violência policial baseada em preconceitos biológicos e morais e em discursos demonizantes e estigmatizantes que a sustentam. Neste quadro, o eufemismo com que definem uma política com ares de genocídio não poderia ser mais cruel: autos de resistência, autos que servem como testemunho para a história da morte de uma população que ainda "teima" em resistir. Isto, é claro, sem contar os "encontros de cadáveres" e demais florilégios que muitas vezes mascaram estes números.

Não se pretende na presente pesquisa, entretanto, formular uma espécie de coletânea de denúncias sobre violências, mas sim analisar os efeitos de uma política criminal levada nestes termos para as crianças moradoras da uma favela pesquisada e

3 Citamos como exemplos: Revista Caros Amigos, setembro de 2008 e In: http://ritv.globo.com/Jornalismo/RJTV/0,,MUL1032559-9099,00-

TRENS+VOLTAM+A+CIRCULAR+DEZ+HORAS+DEPOIS+DE+TIROTEIO+NA+ZONA+OESTE.html

${ }^{4}$ Morel, Benedict-Augustin (2008). Tratado das degenerescências na espécie humana, Rev. latinoam. psicopatol. fundam. [online], vol.11, n. 3.

${ }^{5}$ Bauman, Zygmunt, (1998). O mal-estar na pós-modernidade, Rio de Janeiro: Jorge Zahar Ed.

${ }^{6}$ Goffman, Erving, (1982). Estigma: Notas Sobre a Manipulação da Identidade Deteriorada, Rio de Janeiro: Zahar Editores.

${ }^{7}$ Dados da Secretaria de Segurança Pública do Estado, disponíveis em http://www.isp.ri.gov.br/. 
chamada de Pasárgada. Tal nomenclatura foi utilizada como forma de se proteger nomes a pedido da direção da escola que viabilizou e autorizou a pesquisa. O nome Pasárgada foi escolhido, ainda, em referência ao texto de Boaventura de Souza Santos ${ }^{8}$. Muitas vezes o retrato pintado pelas crianças pesquisadas sobre o lugar onde moram o mostra como uma espécie de lugar perfeito, o que nos permitiria algumas aproximações com o lugar ideal de Manuel Bandeira. Apesar disso, não nos detivemos na pesquisa na análise de possíveis amizades com o rei ou até mesmo a existência de um rei em Pasárgada, mas nos preocupamos especialmente em analisar como a presença da polícia e as operações policiais retiram de Pasárgada toda a sua paz, na visão destas crianças, desde já criadas no que Gizlene Neder chamou de pedagogia da violência ${ }^{9}$.

Assim como verifica Boaventura em sua pesquisa, também nesta Pasárgada as batidas e operações policiais são tão ineficientes do ponto de vista de objetivos policiais quanto repugnantes para os moradores, fazendo com que a polícia seja vista como força hostil e com funções estritamente repressivas. A visão que as crianças mostram na pesquisa, de uma polícia truculenta, violenta e arbitrária, imagem relatada em inúmeras histórias de invasões a residências e espancamentos, sem falar das mortes propriamente ditas, reforça muito esta posição. Seria a favela uma Pasárgada imaginária sentida pelas crianças no momento da ausência da polícia, momento em que poderiam viver "em paz" na favela.

Levando em consideração que as instituições de controle social não são entidades autônomas, mas respondem a uma determinada demanda por ordem presente na sociedade, o que se pretende neste trabalho é analisar de forma crítica o que a construção e associação da pobreza ao mal produz nas subjetividades das crianças moradoras da favela estudada, os "meninos impossíveis"10, e que tipo de infância é construída a partir de uma política criminal que Nilo Batista acertadamente classificou como política criminal com derramamento de sangue, que usa o extermínio como tática de aterrorização e controle social ${ }^{11}$.

\footnotetext{
8 Santos, Boaventura de Souza (1999). Notas sobre a História Jurídico-Social de Pasárgada. In: http://br.geocities.com/b3centaurus/livros/s/boavpassar.pdf.

${ }^{9}$ Ver Neder, Gizlene. (1994) "Pedagogia da Violência”, In: Violência e Cidadania, Porto Alegre: S. A. Fabris Editor.

${ }_{11}^{10}$ Lima, Jorge de (1997). Jorge de Lima: poesia, Rio de Janeiro: Agir.

${ }^{11}$ Batista, Nilo (1998). Política Criminal com derramamento de sangue. In: Revista Discursos Sediciosos Crime, Direito e Sociedade, n. 5/6. Rio de Janeiro: Freitas Bastos Editora/ Instituto Carioca de Criminologia, p. 77-94.
} 
Assim, a hipótese central do presente trabalho vai no sentido de que a política

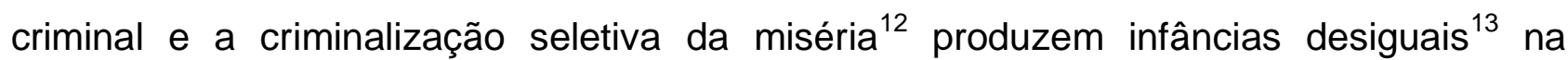
estratégia de gestão da pobreza no capitalismo tardio. Desiguais no sentido da construção de discursos e estratégias diferentes para lidar com a "criança" (ligada a instituições como família e escola e em relação à qual não são necessários maiores cuidados) e com o "menor" (oriundo de família pobre, sempre "desestruturada" e que parece, nos termos do episódio narrado por Gisálio Cerqueira sobre o encontro de um soldado da Polícia Militar com um menino de rua na Cinelândia, representar a "semente do mal"14).

Para tanto, optou-se pela realização da investigação através de três caminhos, a partir de uma escola pública da cidade do Rio de Janeiro em que os estudantes eram todos moradores de Pasárgada: análise de redações, discussões em grupo com as crianças e análise de desenhos.

As discussões em grupo foram realizadas com base na leitura de Graue e Walsh ${ }^{15}$, que chamam atenção para algumas dificuldades na realização de entrevistas com crianças, uma vez que estas, diante de perguntas e questionamentos de adultos, muitas vezes ficam intimidadas por tentar fornecer não uma resposta de acordo com o que sentem, mas uma resposta que pensam que o adulto considere a resposta correta. Neste sentido, a opção por trabalhos em grupo foi retirada dos ensinamentos dos autores como forma de dar maior liberdade e confiança para as crianças no momento de uma resposta ou fala espontânea. Tal opção se mostrou bastante produtiva, uma vez que a fala menos envergonhada de algumas crianças e a espontaneidade dos menos tímidos acabou por contagiar os demais nas entrevistas e fazer com que muitos deles falassem e relatassem suas experiências. No total, foram realizados três encontros com as crianças, todos com duração de aproximadamente duas horas e contando com a presença dos professores, que atuaram no sentido de facilitadores do contato, realizando as devidas apresentações e abrindo espaço em sala para as conversas.

\footnotetext{
${ }^{12}$ Wacquant, Loïc (2003). Punir os pobres: a nova gestão da miséria nos Estados Unidos, Trad. Eliana Aguiar, 2. ${ }^{a}$ ed., Rio de Janeiro: Revan.

${ }_{13}^{13}$ Nascimento, Maria Lívia do (2002). PIVETES: a produção de infâncias desiguais. Niterói: Intertexto; Rio de Janeiro: Oficina do Autor.

${ }^{14}$ Mídia e Violência Urbana. Relatos. Seminário realizado no hotel Glória, Rio de Janeiro, 1 e 2 de julho de 1993. Rio de Janeiro: FAPERJ, 1994. pp. 166/167.

${ }^{15}$ Graue, M. Elizabeth e Walsh, Daniel J (2003). Investigação Etnográfica com crianças: teorias, métodos e ética. Tradução de Ana Maria Chaves. Lisboa: Serviço de Educação e Bolsas - Fundação Calouste Gulbenkian.
} 
Foi também realizada a análise de desenhos, partindo-se da lição de Gisálio Cerqueira de que não é possível identificar um sofrimento senão pela estética ${ }^{16}$. Além disso, a metodologia utilizada pelo historiador Reinhart Koselleck ${ }^{17}$, ao buscar nos sonhos de presos em campos de concentração as formas de realização do terror, que os perseguia até mesmo em seus sonhos, possibilitou a escolha desta fonte não só pela possibilidade de aproximação das favelas cariocas com campos de concentração, como pela possibilidade de investigação através de formas não convencionais, misturando, de alguma forma, ficção e realidade.

Ainda sobre os desenhos, outro aporte teórico importante foi dado por Maria Isabel Ferraz Pereira, Leite quando afirma que os desenhos infantis, assim como qualquer criação, nunca partem do nada, tendo sempre uma referência anterior de conhecimento para que possam fluir. Assim, ainda segundo a autora, o desenho infantil teria, mais do que pelos seus resultados, mas por sua forma de constituição, um papel fundamental na interpretação da compreensão e da análise crítica da sociedade por parte da criança ${ }^{18}$. Os desenhos são, portanto, importantes formas de manifestação das crianças e sua análise é fundamental para tentar explorar como sentem a questão criminal. Sendo assim, a pesquisa se deteve na análise de desenhos coletados pelas professoras quando tinham alguma pertinência com a questão criminal objeto do presente trabalho. Assim, alguns dos desenhos obtidos dentre as crianças de seis anos foram realizados espontaneamente e entregues em diferentes épocas da pesquisa, sendo, no entanto, a maioria realizada dentro de atividades propostas pelos professores em sala de aula, tais como desenho sobre violência (sem maiores explicações ou direcionamento) e desenhos sobre o tema: "O lugar onde eu moro". No total, foram obtidos e analisados 31 desenhos de alunos de 6 anos e 5 desenhos de alunos de 10 anos.

Foram, ainda, analisadas redações dos alunos mais velhos, num total de 71 redações, realizadas sobre temas propostos pelos professores a partir de conversas realizadas sobre a pesquisa e indicações dadas que tentavam dar conta de perceber os sentimentos envolvidos na questão criminal. Assim, propusemos alguns temas aos professores, que pediram as redações aos alunos de acordo com as suas possibilidades

\footnotetext{
${ }^{16}$ Cerqueira Filho, Gisálio e Neder, Gizlene (1997). Emoção e Política: (a)ventura e imaginação sociológica para o século XXI. Porto Alegre: Sérgio Antonio Fabrs Editor.

${ }^{17}$ Koselleck, Reinhart (2006). "Terror e sonho: anotações metodológicas para as experiências do tempo no Terceiro Reich" In: Futuro Passado: Contribuição à semântica dos tempos históricos, Tradução, Wilma Patrícia Maas, Carlos Almeida Pereira; revisão César Benjamin. Rio de Janeiro: Contraponto-Editora. PUCRio.

${ }^{18}$ Pereira Leite, Maria Isabel Ferraz (1998). "Desenho infantil: Questões práticas e polêmicas", In: Infância e produção cultural, Sonia Kramer, Maria Isabel Ferraz Pereira Leite (orgs.). Campinas: Papirus.
} 
de trabalho. As redações estão divididas da seguinte forma: 27 sobre morar em Pasárgada, 21 sobre violência e 23 sobre o tema "polícia e bandido".

Em relação ao material a ser analisado, levou-se em consideração a advertência metodológica feita por Boaventura de Souza Santos em seu trabalho sobre Pasárgada, no sentido de se reconhecer as limitações que a entrevista carrega enquanto método, no caso as entrevistas realizadas em grupo, devendo o pesquisador estar atento a isto de forma a se evitar que eventuais lacunas nas respostas sejam preenchidas com sobreinterpretação $^{19}$. Neste sentido, cabe também a importante advertência feita por Foucault no sentido de não tentar dizer a verdade da verdade dita pelo sujeito. Ou seja, é preciso interpretar, mas também saber ouvir o que dizem as fontes. ${ }^{20}$

Trabalhou-se, ainda, com o método indiciário proposto por Carlo Ginzburg ${ }^{21}$ para a análise do material coletado. Trabalhar com o método indiciário significa trabalhar com procedimentos epistemológicos que priorizem a investigação científica com base em sintomas, pistas e indícios, concentrando a análise em dados marginais, nos detalhes e em resíduos daquilo que é considerado pelas correntes tradicionais da ciência social como o foco principal de análise. Esta noção permitiu a liberdade do presente trabalho para analisar também como fontes os desenhos das crianças, fonte de pesquisas não muito usual no campo das ciências sociais.

Importante ressaltar, no entanto, que o que esta metodologia propõe, longe de "provar o que quiser com poucos dados", como algumas vozes apressadas logo sentenciam para invalidar métodos diferentes de análise, é a atenção a indícios mínimos que podem revelar fenômenos bem mais gerais, muitas vezes escondidos nos pontos normalmente mais observados da análise tradicional, como por exemplo a visão de mundo de uma classe social ou de um determinado autor. ${ }^{22}$ Neste sentido, Gizlene Neder e Gisálio Cerqueira Filho vão destacar a importância de se estar atento a aspectos subjetivos presentes nos estudos históricos, buscando, nas metáforas, metonímias e atos falhos presentes nas fontes estudadas, indícios que podem nos revelar aquilo que um texto ou autor diz sem ter a intenção de dizer ${ }^{23}$. A proposta aqui é a do diálogo, da produção do conhecimento a partir e com as fontes recolhidas e não de um enorme

\footnotetext{
${ }^{19}$ Santos, Boaventura de Souza (1999). Op. Cit.

${ }^{20}$ Foucault, Michel (2007). História da Sexualidade I: A Vontade de Saber, tradução de Maria Thereza da Costa Albuquerque e J. A. Guilhon Albuquerque. Rio de Janeiro, Edições Graal.

${ }^{21}$ Ginzburg, Carl (1990). "Sinais: Raízes de um paradigma indiciário", In: Mitos, Emblemas, Sinais: Morfologia e História. São Paulo: Companhia das Letras.

22 Ginzburg, Carlo (1990). Op. Cit.

${ }^{23}$ Cerqueira Filho, Gisálio e Neder, Gizlene (1997). Op. Cit.
} 
acúmulo de provas e dados que muitas vezes somente servem para confirmar posições anteriormente estabelecidas pelo pesquisador. É preciso interpretar e pensar a partir das fontes e não somente "provar" com elas e é neste sentido que pensamos ser essa metodologia a forma adequada para a análise que empregamos.

\section{Política criminal e a produção de subjetividades}

Com o intuito de adentrar na discussão deste tópico, é importante ressaltar a advertência feita por Foucault sobre uma tendência no campo social de sempre descrever o poder como algo negativo e impeditivo. Para o autor, o poder também produz e constrói realidade. Tal noção é fundamental para se entender as consequências e a produção de subjetividades que se origina do controle social na forma como ele é exercido no Rio de Janeiro. Neste sentido, Foucault chama atenção para o fato de que a repressão direta nem sempre é fundamental e vitoriosa, nos levando a pensar sobre dispositivos diferentes de repressão, no terreno da micropolítica, como dispositivos de saber, de verdade e de prazeres que são descritos como mecanismos positivos, produtores de saber e multiplicadores de discursos produtores de poder $^{24}$.

Para Foucault, segundo o que define como uma teoria do desejo, o desejo e o poder nasceriam juntos. Assim, segundo o autor a lei seria constitutiva do desejo e da falha que o instaura. Em suas palavras:

A correlação de poder já estaria lá onde está o desejo: ilusão, portanto, denunciá-lo numa repressão exercida a posteriori; vão, também, para a cata de um desejo exterior ao poder. ${ }^{25}$

Dessa forma, ao contrário das teorias que dão conta de que o poder é exterior ao desejo e se situaria na repressão dos instintos, para Foucault o poder seria considerado como constitutivo do desejo, não tendo somente a potência do não, mas sendo produtor de sentidos. Não deveríamos, portanto, observar somente uma concepção jurídica e repressora do poder, uma vez que esta concepção elidiria toda a positividade que o poder contém. Assim, o autor lança a seguinte pergunta: por que há a tendência de somente reconhecer o poder em sua forma negativa e de interdição? Isto se explicaria pelo fato de que é somente mascarando uma parte de si mesmo que o poder se torna tolerável, uma vez que não seria "aceito" se fosse inteiramente cínico. Nesta linha de raciocínio, o poder encarado somente como limite à liberdade, como algo negativo e repressor seria, assim, a

\footnotetext{
${ }^{24}$ Foucault, Michel (2007). Op. Cit.

${ }^{25}$ Foucault, Michel (2007), Op. Cit. p. 92.
} 
fórmula geral de sua aceitabilidade. Concluindo com o autor, orientamos os estudos sobre o poder para uma visão que privilegia o seu objetivo, eficácia tática e capacidade de construção e não somente a lei e a interdição ${ }^{26}$.

Trabalhando com os efeitos do que definem como cultura de massas do capitalismo, Félix Guattari e Suely Rolnik também chamam atenção para a produção de sentidos na manifestação do poder através da produção de subjetividades capitalísticas. $\mathrm{Na}$ opinião dos autores, precisaríamos recusar e superar esta divisão para levar em consideração os verdadeiros componentes criadores da subjetividade. Isto porque o desejo sempre apareceria no debate como algo nebuloso e desorganizado, que precisa ser disciplinado, castrado. Entretanto, é o desejo parte constitutiva do poder e não algo separado deste. Tal separação é política e visa à construção de "novos" ou "adequados" desejos no processo de subjetivação capitalista. Assim, a referência no âmbito do desejo ao caos, segundo os autores, viria sempre acompanhada de uma visão através dos óculos da modelização dominante.

Estas considerações acerca do desejo e dos processos de subjetivação e produção atrelados ao exercício do poder na micropolítica nos fornecem subsídios para que possamos analisar de que forma o controle social pode ser um importante instrumento de análise que nos permita adentrar o território da produção desejante na cidade do Rio de Janeiro.

Neste sentido, buscamos direcionar a pesquisa para os efeitos subjetivos do controle social nas mentalidades das chamadas classes subalternas. Assim, com o objetivo de mapear aquilo que o controle social pode vir a criar no terreno dos sentidos, buscamos entender os reflexos subjetivos de uma política criminal seletiva e com bastante "derramamento de sangue" ${ }^{27}$. Essa visão sobre o poder como constitutivo do desejo reforça a importância de se refletir também acerca do controle social informal. Isto porque, ao lado de pensar em um controle que atua de forma repressiva, é fundamental refletir sobre as formas constitutivas que este poder pode assumir. Deste modo, encaramos o controle social informal como seus reflexos no imaginário das classes subalternas pelo espetáculo gerado pelo terror das violentas invasões policiais, mais do que as ações repressivas e violentas propriamente ditas, num projeto de controle do espaço urbano da cidade do Rio de Janeiro.

\footnotetext{
${ }^{26}$ Foucault, Michel (2007). Op. Cit.

${ }^{27}$ Batista, Nilo (1998). Op. Cit.
} 
Dentro do que afirma $\mathrm{Neder}^{28}$ ao analisar um contexto de produção de imagens de terror e medo na imprensa da cidade, a relação deste controle informal com o que chama de internalização do medo e da disciplina nas classes subalternas é muito forte. Assim, trabalhando em cima do pensamento da autora e pelo que foi observado no decorrer da pesquisa, é possível observar como ainda existiriam em Pasárgada as famosas praças públicas da época dos autos de fé da Inquisição ${ }^{29}$, com o terror das operações e revisões ${ }^{30}$ funcionando como importante forma de intimidação e controle para seus moradores, por um lado, e, por outro, como demonstração da eficiência "espetacular" do estado para as classes dominantes.

\section{Medo branco e outros medos}

Buscando os efeitos do exercício deste tipo de controle, o trabalho foi construído a partir das pesquisas de Vera Malaguti Batista, que enfatiza a questão do medo branco ${ }^{31}$, e a partir das pesquisas de Gizlene Neder sobre o que define como as fantasias absolutistas de controle social total e obediência cadavérica ${ }^{32}$ das elites da cidade do Rio de Janeiro, buscando os reflexos destas duas pesquisas nas classes subalternas, que, segundo Neder, seriam levadas a compreender (ao nível da razão) e também a ver e a sentir (memória psicoafetiva) o seu lugar na hierarquia social da cidade ${ }^{33}$.

Assim, buscando uma análise sobre o medo, mas através de um outro enfoque, agora não do medo branco que dispara técnicas de controle, mas de outros medos que estão presentes nas crianças taxadas pelo estigma de menor, além de uma análise sobre a política criminal com derramamento de sangue ${ }^{34}$ que Nilo Batista denuncia, buscamos analisar as crianças e suas formas de significar toda esta relação.

Destacando a importância do medo como técnica de controle social fundamental na história carioca, Vera Malaguti Batista realiza importante estudo acerca da história do medo na cidade do Rio de Janeiro através, por um lado, dos registros da década de 30 do século XIX, nos quais analisa a conjuntura da Revolta dos Malês, em 1835 na Bahia, e

\footnotetext{
${ }^{28}$ Neder, Gizlene (2005). Criminalização da Miséria e Imagens do Terror: uma abordagem transdisciplinar. In: Confluências - Revista Interdisciplinar de Sociologia e Direito oㅜ 3. Niterói, setembro.

${ }^{29}$ Neder, Gizlene (2005), Op. Cit.

${ }^{30}$ Conforme relatado pelos alunos na pesquisa, revisão seria o dia em que a polícia invade a favela, entrando, sem autorização, nas casas dos moradores para verificar se está tudo em ordem.

${ }^{31}$ Batista, Vera Malaguti (2003). O medo na cidade do Rio de Janeiro: dois tempos de uma história. Rio de Janeiro: Revan.

${ }_{32}$ Neder, Gizlene (1997). Cidade, identidade e exclusão social. Revista Tempo, Volume 2, n. 3, junho, Departamento de História da UFF.

${ }^{33}$ Neder, Gizlene (2005). Op. Cit.

${ }^{34}$ Batista, Nilo (1998). Op. Cit.
} 
suas repercussões sobre o medo branco na capital do império; e, por outro lado, através da análise da conjuntura política e econômica da década de 90 do século XX. Segundo a autora, a Revolta dos Malês foi um marco no imaginário do medo e da histeria da época e, apesar de massacrada pelas forças repressivas, implicou em um aumento do controle sobre a movimentação dos escravos, uma vez que os malês, de certa forma, personificavam toda uma luta entre civilização e barbárie ${ }^{35}$.

Sendo assim, buscando trabalhar com a disseminação do medo e do caos como técnicas que servem para detonar estratégias de neutralização e disciplinamento das massas empobrecidas, Batista busca trabalhar os discursos dominantes às épocas como forma de analisar, mais do que aquilo que proclamam, aquilo que escondem. Em suas palavras, sua hipótese central vai no sentido de que “(...) a hegemonia conservadora de nossa formação social trabalha a difusão do medo como mecanismo indutor e justificador de políticas autoritárias de controle social'36.

A necessidade de um medo desproporcional a legitimar a realidade era fundamental para manter as violentas políticas de controle sobre os oprimidos do regime escravocrata. Na formação brasileira, como afirma Batista, liberalismo e escravidão conviveram ao tempo, já que a Constituição dita Liberal de 1824 garantia o direito à propriedade em toda a sua plenitude, mantendo a escravidão. Neste sentido, nem o fim da escravidão e nem a posterior proclamação da República romperam com o que Neder denomina de fantasias absolutistas de controle social total e obediência cadavérica, considerando Batista as operações da polícia nas favelas hoje como prova viva deste legado. Desta feita, esse medo, caracterizado como medo branco pelas autoras, aumenta com o fim da escravidão e proclamação da República, produzindo uma República excludente, intolerante e truculenta, caracterizada por seu projeto político extremamente autoritário e voltado contra as chamadas classes perigosas ${ }^{37}$.

O importante a ser ressaltado nessa interpretação é o papel constitutivo do medo na formação social brasileira, uma vez que a sua difusão se torna fundamental para induzir e justificar políticas autoritárias de controle social, uma importante marca na formação da cidade. Neste contexto, a difusão de imagens do terror como espetáculos de sangue é fundamental para a disseminação do medo e é caracterizada por Batista como

\footnotetext{
${ }^{35}$ Batista, Vera Malaguti (2003). Op. Cit.

${ }^{36}$ Batista, Vera Malaguti (2003). Op. Cit. p. 23.

${ }^{37}$ Batista, Vera Malaguti (2003). Op. Cit.
} 
importante permanência da cultura ibérica ${ }^{38}$. Definindo o medo como projeto estético da modernidade, Batista cita Neder para discorrer acerca de toda uma produção imagética de terror através de jornais, revistas e televisão como forma de constituição de uma ideologia dominante e de subjetividades apropriadas à ordem social que se queria manter. Neste sentido, manter liberalismo com escravidão implicava em aceitar um liberalismo que não rompesse com as matrizes ibéricas, aceitando e mantendo a hierarquização social absolutista e estratégias de suspeição e culpa do direito canônico, fundamentais para o controle social. O medo e sua disseminação, através do que Neder denominou de visões hiperbólicas sobre as classes perigosas, dessa maneira, seriam fundamentais para garantir a estrutura social e a inviolabilidade da vontade senhorial.

Dentro do contexto da década de 30 do século XIX, com a disseminação de algumas revoltas influenciadas pela Revolta dos Malês, o medo fica ainda mais em evidência, disparando mais repressão e um clamor por intervenções mais fortes do Estado para conter estes levantes e manter a estrutura social. O que interessava era reprimir para garantir a ordem burguesa e a vontade senhorial, com a polícia atuando majoritariamente na garantia de uma determinada ordem pública utilizando, como hoje, a tortura como objetivo e não como método. Os castigos físicos eram frequentes e nos revelam como esta permanência ainda é forte na sociedade, com a naturalização da violência policial cotidiana dirigida seletivamente contra negros e pobres ${ }^{39}$. $O$ objetivo da guarda era reprimir, subjugar e infundir terror como forma de garantir à força a manutenção de uma ordem penal que interessava à hierarquização social.

Em nossa interpretação, a importância do trabalho consiste em demonstrar, com a comparação entre duas épocas históricas distintas, que “(...) esses clamores advindos do pânico cobram sempre o seu preço no corpo dos oprimidos e transformam-se rapidamente em discursos que matam. ${ }^{40}$

Assim, analisando as consequências estéticas destes discursos de medo, analisando aquilo que entra pelos olhos no cotidiano da cidade, é importante a referência que faz Batista ao conceito de pântano de Foucault, como conceito que simbolizaria as áreas pobres como locais de contaminação e contágio, que deveriam ser evitadas para evitar o perigo daquilo que representasse a estética da escravidão ${ }^{41}$.

\footnotetext{
${ }^{38}$ Batista, Vera Malaguti (2003), Op. Cit.

39 Batista, Vera Malaguti (2003), Op. Cit.

40 Batista, Vera Malaguti (2003), Op. Cit. p. 192.

${ }^{41}$ Batista, Vera Malaguti (2003), Op. Cit.
} 
Neste sentido, observa-se como a difusão e hiperbolização ${ }^{42}$ do medo funciona como reforço para a criminalização seletiva da miséria e para o clamor por políticas públicas mais repressivas, numa espécie de populismo criminológico, ou autoritarismo $\operatorname{coo}^{43}$. Tal forma autoritária atuaria por meio da hiperbolização dos discursos do medo, ofuscando debates e produzindo o discurso único que clama como alternativa sempre mais repressão e controle.

Interessante e ilustrativo exemplo da continuidade e da permanência do medo como método de controle nos é dado por Vera Malaguti quando mostra em sua pesquisa alguns jornais da época da Revolta dos Malês, em que predominam reivindicações de mais controle sobre os africanos, reclamações pelos níveis "insuportáveis" e "intoleráveis" de violência, reivindicações que, pela semelhança com as dos jornais de hoje, são capazes de dar conta de como ainda é fundamental a manipulação do medo. Resumidamente, naquele contexto, como no da pesquisa que este artigo aborda, o clamor era por uma polícia que desse confiança aos "homens de bem" e, aos escravos negros, infundisse o terror.

Chega-se aqui a dois pontos muito importantes: confiança e terror; confiança e medo. Mas de que medo se está falando, que outro medo é esse que não o medo branco? Seria uma espécie de outra face do medo, para utilizar emprestado um conceito que Loïc Wacquant utiliza para falar do gueto no livro As duas faces do gueto ${ }^{44}$.

Para entender este medo, é fundamental a referência a uma conferência dada por Carlo Ginzburg, no ano de 2006, no Laboratório Cidade e Poder, recentemente publicada e que se intitula Medo, reverência e terror: reler Hobbes hoje ${ }^{45}$. Nesta conferência, Ginzburg retoma a noção de Hobbes e do pacto social para ressaltar um importante aspecto desta ideia: de acordo com o autor, o pacto que cria o Estado seria um pacto baseado no medo. Desta maneira, o Estado atuaria como um poder que mantém os homens em estado de sujeição ou reverência, ou seja, manipularia o medo para orientar as suas ações para o "bem comum" (saindo da conhecida "guerra de todos contra todos").

\footnotetext{
${ }^{42}$ Utiliza-se aqui o termo utilizado por Neder, Gizlene (1997). Op. Cit.

${ }^{43}$ Zaffaroni, Eugenio Raul (2007). O inimigo no Direito Penal. Tradução de Sérgio Lamarão. Rio de Janeiro: Revan, p. 269. Zaffaroni caracteriza o que chama de autoritarismo atual como autoritarismo cool, relacionado com a moda e em relação ao qual a adesão se daria como obrigação para não ser estigmatizado, devendo o discurso único que clama por vingança e mais penalidade ser repetido como forma de estar na moda. O discurso do autoritarismo $\mathrm{coo} /$ seria reduzido a pura mensagem publicitária, com o predomínio de imagens e a venda de poder punitivo enquanto mercadoria funcionando como remédios midiáticos contra frustrações e inseguranças causadas pelo nosso modelo social.

${ }^{44}$ Wacquant, Loïc (2008). As duas faces do gueto, São Paulo: Boitempo.

${ }^{45}$ Ginzburg, Carlo (2008). Fear, reverence terror: reading Hobbes today. In: European University Institute, Max Weber Lecture Series - MWP - 2008/ 05, Badia Fiesolana, Italy.
} 
Como é possível observar, está se falando aqui de um outro medo, que não o medo branco descrito por Neder e Batista, mas um medo em relação ao Estado, através do terror (mescla de medo e sujeição). Seria, portanto, o medo a base da origem do Estado, centrado numa ideia de controle social oficial que pudesse, de certa maneira, dobrar com o terror a vontade e o desejo.

Interpretando o que ressalta Ginzburg, seria a criação do Estado uma espécie de fuga do terror da guerra de todos contra todos. Entretanto, tal fuga se daria em direção a uma espécie de "oficialização do terror", ou seja, a uma concentração do "direito" de incutir terror nas mãos de um órgão oficial. Desta maneira, seria a fuga do terror da guerra de todos contra todos, para a ditadura do Estado e a guerra de alguns contra os outros, contra os diferentes. É possível observar aqui grande aproximação com o momento atual, se observarmos os discursos oficiais e dominantes que associam pobreza e miséria a uma espécie de selvageria que autoriza e precisa do controle para que saia da "guerra" em que vivem e para que, principalmente, esta guerra não faça vítimas entre as elites. De certa maneira, com a exacerbação deste controle, assiste-se, na verdade, a um aumento do terror do Estado que se legitima em nome da manutenção do próprio Estado, ou seja, o poder antes "pactuado" para que se mantivesse a "paz" é agora utilizado para que se mantenha este próprio poder e a ordem que ele institui.

Na sua proposta de adaptação de Hobbes para hoje (no contexto do século XXI), ressalta Ginzburg a importância que assume a difusão do terror tecnológico como forma de se criar submissão e exatamente neste sentido é que se pretende dirigir a interpretação de alguns dos resultados obtidos na pesquisa com as crianças para que se possam tecer algumas considerações acerca da importância do terror e do medo como técnicas de controle das classes subalternas.

\section{A construção da diferença: a criança e o menor}

Em importante pesquisa sobre o que chama de menoridade na cidade do Rio de Janeiro $^{46}$, Adriana de Resende Vianna analisa o processo de construção do que define como o personagem social chamado de menor através da atuação da polícia no seu recolhimento das ruas e classificação. Trabalhando estes menores enquanto alvos de violências cotidianas e desapercebidas por serem considerados pelo senso comum como a sujeira a ser removida das ruas, a autora trabalha com os processos simbólicos de

\footnotetext{
${ }^{46}$ Vianna, Adriana de Resende Barreto (1999). O mal que se adivinha: polícia e menoridade no Rio de Janeiro, Rio de Janeiro: Arquivo Nacional.
} 
desumanização destas crianças e a ação policial que recai sobre eles pela razão de serem considerados como um mal ainda por se concretizar, ou seja, um mal que se adivinha. Assim, àquelas crianças desvalidas e consideradas miniaturas de facínoras, segundo a autora, seria reservado o termo menor, como consequência da interação entre a polícia e as crianças pobres e com significados absolutamente distintos dos que normalmente são associados às ideias de infância.

A autora afirma o período de 1910-1920 como época em que ocorre a cristalização e naturalização dos significados do termo menor, fazendo com que o termo tenha uma importante função simbólica no sentido de retirar determinados indivíduos de um domínio da infância e de toda uma rede de proteções que se estabelece em torno dela, permitindo a consolidação de toda uma desigualdade no acesso a direitos entre os menores e as crianças. Ligado à prática das ações policiais, o termo menor pode ser definido como fruto de um processo de produção de identidades pela atuação da polícia, num processo de aprendizagem dirigido às crianças pobres como forma de afirmação de seu status social $^{47}$.

No caso de Pasárgada, a atuação policial violenta faz com que esta construção exista sem a necessidade de passagem oficial pelas instituições do Estado, numa interação em que aprendem que não são crianças, mas menores. Talvez esta possa ser caracterizada como uma espécie de "evolução" desta forma de controle e herança que o simbolismo do termo legou à geração atual. O fato é que as crianças entrevistadas têm muito medo da polícia e são corriqueiramente levadas a conviver com as mais diversas arbitrariedades policiais que a todo tempo Ihes passam a mensagem sobre qual o lugar que ocupam na dinâmica social.

Entretanto, em Pasárgada, o menor é produzido não em um contexto de interação particular, mas como instrumento geral de controle. Mesmo diante destas diferenças, permanece uma importante questão na definição destes menores: naquela época, como agora, a margem de julgamento e intervenção policial em relação ao menor são bastante ampliadas e o menor permanece, como afirma a autora, como importante critério organizador das relações sociais ${ }^{48}$. A atuação policial hoje permanece com um forte potencial hierarquizador das relações sociais e seus agentes atuam, portanto, no sentido de viabilizar e ampliar todo um processo de construção de desigualdades políticas.

\footnotetext{
${ }^{47}$ Vianna, Adriana de Resende Barreto (1999), Op. Cit.

${ }^{48}$ Vianna, Adriana de Resende Barreto (1999), Op. Cit.
} 
Tal construção teórica da pesquisadora sobre esta atuação faz bastante sentido ao analisarmos as relações estabelecidas entre as crianças e a polícia em Pasárgada. Lá, estas crianças estão a todo momento expostas a uma grande violência e a toda sorte de arbitrariedades que lhes passa a mensagem de medo e de qual lugar ocupam na hierarquia social. A atuação policial se dá não mais no sentido de criar e classificar, mas numa espécie de "tratamento" pedagógico violento ${ }^{49}$, uma vez que, já sabendo onde se encontram os menores (sempre nas áreas pobres) atua a polícia demonstrando, através da violência, quem manda no local e quem deve obedecer, reforçando e internalizando o controle na população infantil pobre. Alguns trechos de diferentes redações escritas pelos meninos pesquisados nos ajudam a entender um pouco deste controle:

Também tem policia que mata gente inocente eles acham que só porque alguns meninos pintam o cabelo de louro é porque é bandido não é assim que tem que ser o mundo.

Os policial brigam com a gente pegam dinheiro. Mas também tem policial que são amigos.

Os policiais fazem operações e saem entrando nas casas das outras pessoas.

Eu acho que a polícia tinha que botar atrás das gradi os bandido não eles matam pessoas inocentes.

Na minha opinião eu acho que as polícias estão muito agressivas com as pessoas. (...) Mas espero que um dia eles pensa positivo e ver quantos inocentes estão matando.

Quando os policias vem a Pasárgada tem tanto tiro que mata muitas pessoas inocente e no final eles vão embora e não se preocupam com as família.

Eu vejo os policiais alguns mesmo são bom a maioria é ruim. Muitas pessoas já morreram e sofreram por causa da polícia.

Mais lá em Pasárgada é muito bom de se morar, quando não tem polícia para estragar a favela.

Como é possível observar, os policiais do bem, apesar de existirem, segundo os relatos, não têm condutas que gerem lembranças na memória psicoafetiva das crianças, que aponta estar muito mais atravessada pela violência policial do que por boas ações ou condutas positivas que estes possam ter. $O$ que se pretende nesta análise não é desqualificar aquilo que foi dito pelas crianças em relação aos bons policiais, até mesmo porque não é o nosso objetivo demonizar a polícia e sim analisar como a sua atuação constrói uma imagem bastante negativa e de medo na cabeça das crianças, chamando atenção para o fato de que, a despeito de escreverem sobre estes comportamentos positivos, não são capazes, em nenhuma redação lida, de dar corpo a estes atos

\footnotetext{
${ }^{49}$ Neder, Gizlene (1994). Op. Cit.
} 
descrevendo algum acontecimento, por exemplo, ao contrário do que ocorre com os bandidos, em que sobram relatos de casos neste sentido. Esta ausência, portanto, pode nos revelar muito sobre como o sentir destas crianças está atravessado pelo medo e pela repressão cotidiana.

Merece também destaque a presença corriqueira nas falas e nas redações escritas da condenação da polícia por matar "pessoas inocentes". A partir do momento em que percebemos que o problema muitas vezes se situa na morte de inocentes, podemos inferir até que ponto uma certa permissividade com a ideia de morte aos bandidos, aos identificados como inimigos, não está de tal forma difundida na memória psicoafetiva destas crianças, fazendo com que considerem como "normal" a violência policial dirigida aos rotulados como bandidos. É como se o problema existisse apenas no momento em que morrem inocentes, sendo os demais passíveis de morte pela polícia.

A distinção entre menor e criança é marca presente até hoje, mesmo com a retirada desta divisão da letra da lei. Verificamos através dos autores estudados como a construção da diferença entre a criança e o menor é historicamente produzida como forma de controle da pobreza. Com as novas tecnologias de controle social, entretanto, o que antes poderia ser tido como forma de disciplinamento objetivando a constituição do mercado de trabalho é hoje encarado apenas em sua forma repressiva e de controle. À multidão de pobres e negros sem perspectivas e empregos, o controle através da violência e da estigmatização é apresentado como forma de dizer a cada um qual é o seu lugar de uma maneira dura o bastante que possa não somente ser ouvida e compreendida, mas sentida.

A pesquisa realizada mostra como esta diferença é bastante viva não só como forma de justificar as ações policiais para a "sociedade", mas, principalmente, como forma de se fazer sentir nas crianças. Assim, enquanto realidade simbólica, a construção persiste e mantém-se extremamente viva. Às crianças, os estudos e a brincadeira, afinal, são o "futuro do país"; aos menores, a repressão e a violência para que, nem em sonho, possam pensar em resistir.

\section{Retratos do medo: os desenhos e algumas conclusões}

$\mathrm{Na}$ pesquisa com as crianças moradoras de Pasárgada foi possível observar, de forma geral, o forte medo que sentem da polícia. Nas redações e nas entrevistas, palavras como terror, invasões, operações, tiroteios, além de relatos de violências dentro das casas e ofensas e agressões aos familiares são presenças tão marcantes quanto 
corriqueiras e dão importantes contribuições para entender como o terror atua na produção de subjetividades ${ }^{50}$ nestas crianças. Também nos desenhos, que passamos agora a analisar, este terror imposto pelas instituições oficiais de controle aparece com bastante clareza.

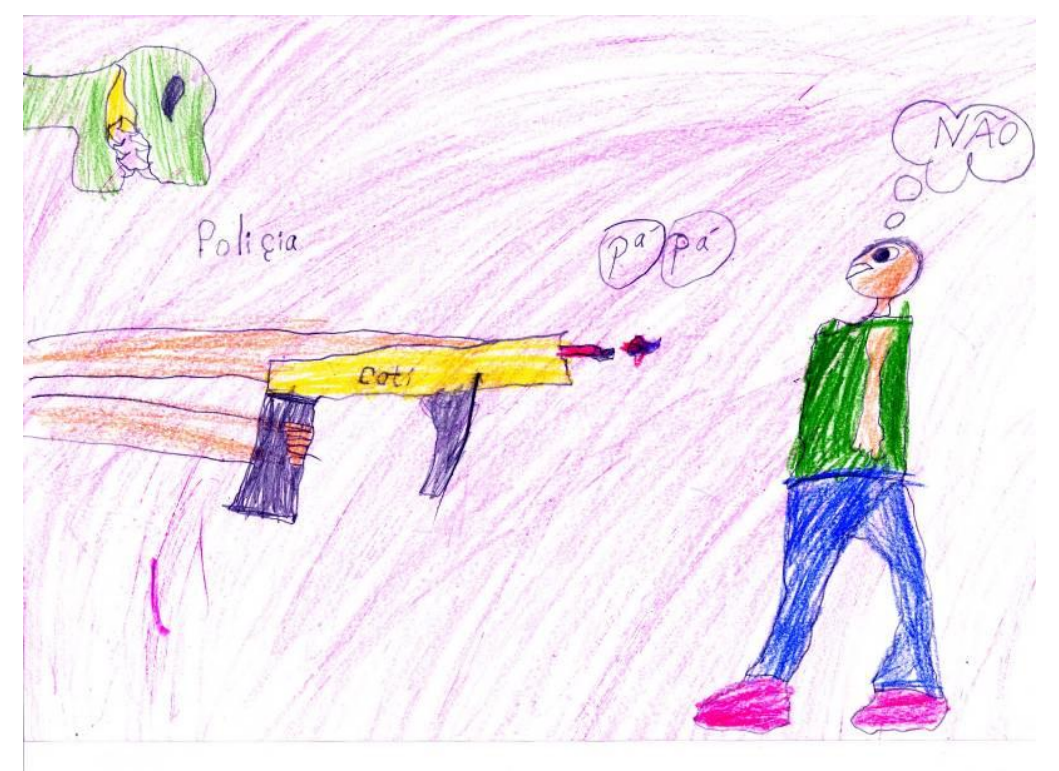

No desenho acima, elaborado por um menino de seis anos em atividade livre, é possível observar um policial com rosto de monstro que atira com um fuzil em um homem que grita: NÃO! Em primeiro lugar, chama atenção a visão da polícia enquanto monstro. Além disso, o conhecimento da criança sobre a arma utilizada pela polícia também aparece, uma vez que a arma utilizada não é uma arma qualquer, mas nomeada. Trata-se do nome de um fuzil, o que demonstra o conhecimento do menino sobre as armas utilizadas pela polícia. O policial do desenho não é um sujeito, mas parece ser mais uma espécie de entidade que povoa as subjetividades destas crianças: é a políçia, forma como é escrito no desenho. Entidade não pelo erro de português cometido, normal para uma criança que está aprendendo a ler, mas por representar a polícia de forma geral, dentro de seu imaginário. É possível confirmar esta análise, ainda, pelo seguinte fato: a imagem não tem corpo, sendo representado apenas por braços que atiram e feições de monstro, de um ser "do mal", com dentes afiados e a expressão de raiva que se observa na face do monstro do desenho.

Além disso, existe um sentimento de afastamento entre o menino e a polícia, que só tem cara de mal e braços que atiram, sem um corpo que possa ser atingido. Outro ponto importante, o homem (ou seria um menino?) do desenho não grita, já que a caixa

\footnotetext{
${ }^{50}$ Foucault, Michel (2007). Op. Cit.
} 
de diálogo apresentada no desenho tem como ligação entre ela e o homem bolinhas soltas no ar, o que nas histórias em quadrinhos é conhecido por representar pensamentos em vez de fala. Neste sentido, pode-se sugerir uma ausência de reação por falta de tempo até mesmo para gritar. Assim, tem o menino do desenho apenas tempo para os seus próprios pensamentos, que "gritam" NÃO. Gritos presumidos pelo tamanho da fonte utilizada no desenho, com a palavra não sendo grafada com uma letra nitidamente maior do que todas as outras palavras do desenho. Aqui, mais do que a dúvida se estamos diante de um homem ou de um menino no desenho, quem grita é o seu autor, é o menino de seis anos que grita através de seu desenho.

Além de representado sem corpo, apenas com braços e cabeça de monstro, notase no desenho ainda uma clara diferença: apesar de ser desenhada com cara de monstro, a polícia é, ao mesmo tempo, desenhada com braços humanos. Entendemos ser este outro alerta do menino, no sentido de chamar atenção para o que chama de monstros, por um lado, e o que vê como realidade de outro. Como alerta Koselleck, terror, sonho e realidade estão aqui intimamente ligados.

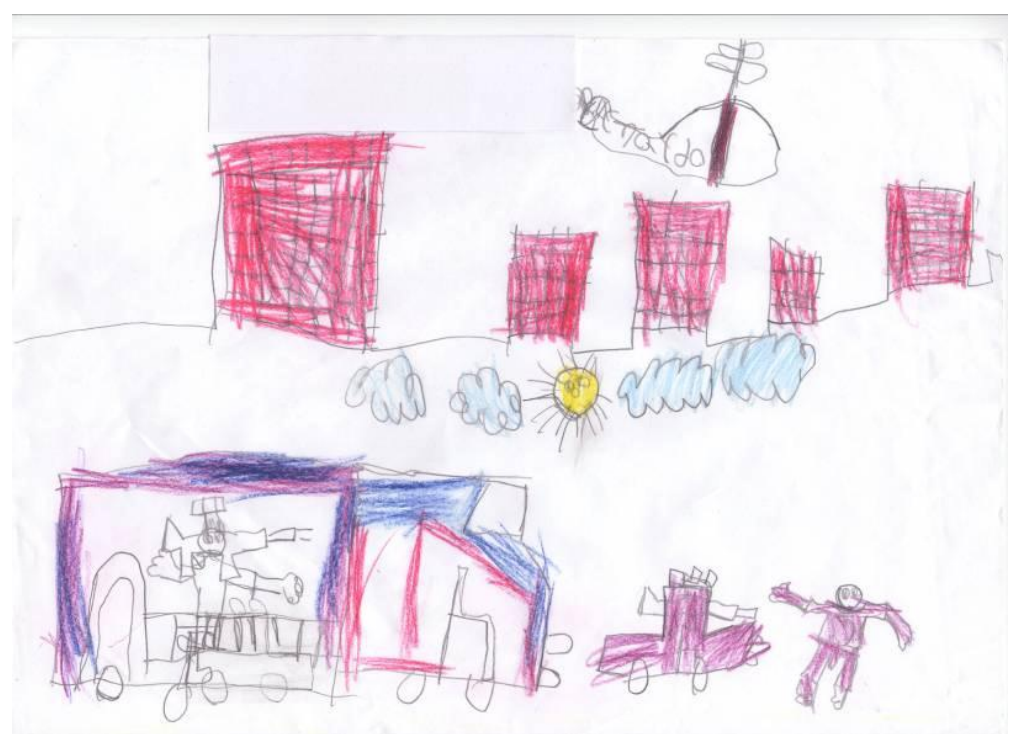

Outro ponto importante do controle que aparece nos desenhos é a clara divisão entre a parte de baixo e a parte de cima da favela. Relatada pelas crianças e presente nos desenhos, esta divisão é importante, pois mostra a separação vista pelas crianças entre os de cima, moradores da favela, e os de baixo, demais moradores da cidade. No desenho acima, observa-se de forma bastante explícita esta divisão, simbolizada, inclusive, pelo céu, que no desenho está situado entre a parte da cidade, representada pela presença do caveirão e da polícia, e o morro. 
No entanto, surge nos desenhos uma figura central nesta divisão, que simboliza a leitura de Ginzburg acerca do terror tecnológico como forma de submissão. Esta figura representa uma espécie de quebra nesta relação. Trata-se do helicóptero. O helicóptero é o grande terror das crianças ouvidas na pesquisa (muito mais do que o caveirão). Talvez por todo o simbolismo que o envolve, pela quebra da relação simples entre os de cima e os de baixo, a presença do helicóptero pairando sobre suas cabeças e vendo tudo que se passa no morro, além, é claro, do fato de atirar para todos os lados, causa uma fobia muito intensa nas crianças. Uma história narrada por uma professora sobre uma menina ajuda bastante a entender esta questão. Chegando à escola em dia de operação policial em Pasárgada, a menina de 7 anos e a professora travam o seguinte diálogo:

- Tia, você já viu um helicóptero?

- Já.

- Mas você não tem medo?

- Medo por quê?

- Ai, tia, eu fiquei com muito medo porque era da polícia!

Reside aqui uma combinação explosiva para subjetividade destas crianças: a terrível junção entre o helicóptero e a polícia. O medo aqui é tão intenso que o helicóptero chega a ser desenhado em um dos desenhos analisados como se soltasse bombas que explodem ao cair sobre a favela, enquanto moradores se acumulam pelo chão e caem dos edifícios como se fossem bonecos mortos. Não há resistência. Ninguém atira para cima. Ninguém sequer porta armas ou ameaça o helicóptero, que, no entanto permanece jogando bombas sobre a favela. Nos desenhos, outro ponto relativo ao helicóptero que chama a atenção é a sua presença sempre no alto das folhas, o que o faz parecer como alvo distante e praticamente inatingível, mas que, no entanto, causa imensos estragos, não só materiais como emocionais, nas crianças, como a sua presença recorrente nos desenhos sugere.

Essa intimidação causada pelo helicóptero já foi muito bem abordada por Cerqueira Filho e Neder, quando afirmam sobre ele:

Sofisticado recurso tecnológico, o helicóptero, com o som ensurdecedor que lhe é típico, espalhando vento, poeira e terror dramatiza a vinculação estratégica pós-modernismo e exclusão social porque absolutista afã de controle social qualquer que seja o objetivo tático na operação ilegal da polícia (intimidar os moradores, intimidar os traficantes, cobrar do tráfico a propina de quarenta mil reais, "queima de arquivo" porque E.J.A. fora testemunha 
involuntária de duplo crime praticado, na véspera, por policiais, repressão policial, etc.). ${ }^{51}$

Assim, observa-se que, mais do que o caveirão, que nos desenhos analisados aparece apenas uma vez, parece ser o helicóptero o grande monstro a habitar os pesadelos destas crianças. Monstro esse que, como afirmam os autores e a leitura dos desenhos indica, é particularmente perigoso por representar uma união entre estratégias e equipamentos pós-modernos de controle e demandas por ordem ainda tributárias do absolutismo.

Através desta análise, foi possível perceber como o medo e terror atuam no sentido de ressignificar simbolicamente, nas práticas policiais, a diferença antes prevista na legislação (e "abolida" com o Estatuto da Criança e do Adolescente, o ECA) entre a criança e o menor. Assim, a despeito de sumir da legislação, os que são considerados anormais pelo modelo de infância são ainda tratados como menores, agindo a polícia como agente privilegiado nesta classificação. No entanto, de forma diversa do contexto narrado por Adriana Vianna no início do século XX, quando tinha a polícia o papel de criar estes menores, sendo assim consideradas as crianças pobres ${ }^{52}$, hoje, tal atuação se dá já não mais somente no sentido de criar e classificar, mas numa espécie de "tratamento" pedagógico violento, uma vez que, já sabendo onde se encontram os menores (sempre nas áreas pobres) atua hoje a polícia demonstrando, através da violência, quem manda no local e quem deve obedecer, reforçando e internalizando o controle sobre a população infantil pobre e fazendo com que a lógica policial ainda seja o recurso para lidar com alguns meninos.

Vemos, portanto, alguns exemplos de como o poder punitivo atua no sentido de construir e manter diferenças historicamente produzidas, servindo de importante forma de neutralização da conflitividade social. O problema é sempre a falta de pena e não mudanças sociais. Concluímos o artigo fazendo referência ao que disse um menino sobre recente proposta da construção de muros cercando as favelas:

Esse muro não serve para nada. Só serve porque eles tem medo de nós.

\footnotetext{
${ }^{51}$ Cerqueira Filho, Gisálio e Neder, Gizlene (1997). Op. Cit. p. 70.

${ }^{52}$ Vianna, Adriana de Resende Barreto (1999). Op. Cit.
} 


\section{Bibliografia}

Batista, Nilo (1998). Matrizes ibéricas do sistema penal brasileiro. Coleção Pensamento Criminológico, no 5. Ed. Freitas Bastos/Instituto Carioca de Criminologia. Rio de Janeiro.

Batista, Vera Malaguti (2003). Difíceis ganhos fáceis - drogas e juventude pobre no Rio de Janeiro. Rio de Janeiro: Revan.

Cerqueira Filho, Gisálio e Neder, Gizlene (1997). Emoção e Política: (a)ventura e imaginação sociológica para o século XXI. Porto Alegre: Sérgio Antonio Fabrs Editor.

Foucault, Michel (2005). A verdade e as Formas Jurídicas. Rio de Janeiro: NAU Editora.

Ginzburg, Carlo (2008). Fear, reverence terror: reading Hobbes today. In: European University Institute, Max Weber Lecture Series - MWP - 2008/ 05, Badia Fiesolana, Italy.

Neder, Gizlene (coord.) (1994) Famílias, Crianças e Exclusão Social - a criança de rua no Rio de Janeiro. Relatório do Projeto de Pesquisa da UFF, Laboratório Cidade, Poder e Memória e UNESCO - IBECC. Rio de Janeiro.

Neder, Gizlene e Cerqueira Filho, Gisálio (2007). Família, Poder e Controle Social: concepções sobre a família no Brasil na passagem à modernidade. In: Idéias Jurídicas e Autoridade na Família. Rio de Janeiro: Revan.

Thompson, Augusto (2007). Quem são os criminosos? O crime e o criminoso: entes políticos. Rio de Janeiro: Editora Lúmen Júris.

Wacquant, Loïc (2008). As duas faces do gueto. São Paulo: Boitempo.

Zaffaroni, Eugenio Raúl (1988). Criminologia: aproximación desde un margen. Bogotá: Temis. 